\title{
Curriculum gaps in teaching clinical skills to Iranian undergraduate medical students
}

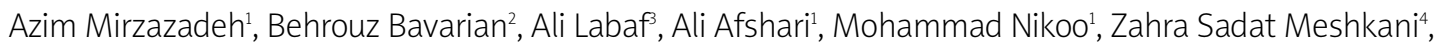
Patricia Khashayar

1Department of Internal Medicine, Imam Khomeini Hospital, Center for Educational Research in Medical Sciences (CERMS), Tehran University of Medical Sciences, Tehran, Iran ${ }^{2}$ Department of Pediatrics, Markaz e Tebbi Hospital, Tehran University of Medical Sciences, Tehran, Iran

${ }^{3}$ Department of Emergency Medicine, Imam Khomeini Hospital, Tehran University of Medical Sciences, Tehran, Iran

${ }^{4}$ Department of Psychology, Tehran University of Medical Sciences, Tehran, Iran

${ }^{5}$ Endocrinology and Metabolism Research Center, Tehran University of Medical Sciences, Tehran, Iran

Submitted: 18 September 2011

Accepted: 13 November 2011

Arch Med Sci 2013; 9, 2: 309-313

DOI: 10.5114 /aoms.2013.33073

Copyright (c) 2013 Termedia \& Banach

\section{Abstract}

Introduction: The inefficacy of clinical skill education during the clerkship has been reported in several studies. The present study was conducted to evaluate the competency of medical students in performing several clinical skills through an Objective Structured Clinical Examination (OSCE), aiming to evaluate the quality of the existing curriculum in the clerkship phase.

Material and methods: The cross sectional study was conducted at the end of the clerkship period, before the students had entered the internship. The OSCE exam was conducted in the morning ( 2 different tracts) and in the evening ( 2 similar tracts) and 86 students participated in the exam. Each tract consisted of seven stations. The students' points in the stations assessing history taking and clinical skills were compared.

Results: The students gained the highest points in the history taking stations, whereas the procedure stations accounted for the lowest points; there was a significant difference between these stations $(p<0.001)$. The female students achieved higher scores in the OSCE exam compared to males $(p=0.004)$.

Conclusions: The OSCE exam revealed the inefficacy of the current medical curriculum in teaching the required clinical skill to undergraduate medical students during the clerkship.

Key words: Objective Structured Clinical Examination, clinical exam, history taking, procedure, station, clerkship.

\section{Introduction}

Skillful performance in the act of medical care is fundamental for providing patients with precise and professional health care. The patient expects physicians to diagnose his/her problem accurately, prescribe a suitable and effective treatment, while maintaining an acceptable and humanitarian relationship with him/her [1].

Clinical skills, therefore, are considered as the core competencies, indicating that the essential goal of medical education is to ensure that each student

\section{Corresponding author:}

Patricia Khashayar MD

Keshavarz Blvd.

Tehran University

of Medical Sciences

Phone: +98 9121725880

Fax: +9822020643

E-mail: patricia.kh@gmail.com 
can perform such skills precisely throughout his/her professional life [2, 3].

Learning clinical skills is a time-consuming and gradual process. Clerkship is the time in which students have to learn and practice various clinical skills. In recent years, however, the adverse institutional, economic and regulatory authorities have diminished the quality of teaching such skills [3].

Many studies have evaluated the competency of clerkship students in performing clinical skills in order to ascertain the deficiencies and help authorities make the necessary changes in the curriculum $[4,5]$. The majority of them reported that these techniques are not systematically taught or comprehensively evaluated during the undergraduate education [6-8].

In our country, similarly, inefficacy of clinical skill education during the clerkship has been reported in several studies $[9,10]$. Except for the study conducted in Shiraz University of Medical Sciences, they have used questionnaires and self assessments to evaluate the students' competency in performing such skills [11]; in other words, not much is performed regarding the paradigm of the quality of medical education and the learner's performance outcome in our country.

The present study was, therefore, conducted to evaluate the competency of medical students in performing certain clinical skills through an Objective Structured Clinical Examination (OSCE) - considered as an acceptable examination technique in evaluating the performance and competence in clinical skills. In other words, the present study aimed to evaluate the quality of the existing curriculum in teaching communication, clinical examination, medical procedures/prescription, and interpretation of results [12], during the clerkship.

\section{Material and methods}

After being approved by the ethical board committee of Tehran University of Medical Sciences, the cross sectional study was conducted on all the undergraduate medical students who had just finished their clerkship, and were intending to start internship in a short time. The university asked the students to participate in the exam, confirming that while the OSCE scores would not have any negative effects, those with the highest scores would be given bonuses in the internship.

In the first step, an OSCE committee consisting of the dean of the Medical University and clerkship phase along with the academic staff with practical experience in designing OSCE exams was established. The 16-member committee determined the date of the exam and the basic clinical skills needed to be evaluated in the exam based on the existing curriculum, literature review [2, 11], AAMC clinical skills of clerkship [3], the complaints received by the Iranian Medical Council and the self assessments taken from the graduates regarding the necessary and frequently used skills. It should be stressed that the authors decided to select the clinical skills based on all the above mentioned evidence as there was no written document pointing out the most important clinical skills an undergraduate student should know before entering the internship.

Considering the limitations of the physical environment of the skill lab, the place in which the exam was supposed to take place, particularly the number of rooms, along with the fact that 7 is the minimum acceptable number of stations in each OSCE exam, the committee decided to hold the exam in two sessions (morning and afternoon), each time in two tracks. It was decided that the morning tracks would be different, whereas similar stations were designed for the tracks of the afternoon exam.

In order to cover the largest number of clinical skills possible in different fields and considering the amount of the undergraduate curriculum dedicated to each course, it was decided to design three stations in surgery, internal medicine, gynecology, and pediatrics, and a single station for ophthalmology, ENT, infectious disease, orthopedics, urology, emergency medicine, dermatology, radiology and neurology.

Each station was supposed to be 5 min long; a 1-minute delay was calculated for the gap between the stations, during which the students were able to study the stations through the instruction placed on the station door. It was decided that the total score of each station would be 10 points. Accordingly, the stations - the candidate instructions, the examiner instructions, the checklist, the simulated patient instruction (if required), and the equipment list - were designed (Table I).

Several sessions, based on the station and the competency of the individual, were held to train the simulated patients and the tutors. The tutors were asked not to talk to the candidates and not to provide them with any clues or feedback. The simulated patients, similarly, were asked to avoid giving additional information; they were also asked to follow the instructions given by the students instead of performing the learned procedures.

Finally, the physical environment of the exam was designed concerning the station design. The candidate instructions were placed both on the door of the station and on the table in the station so that the student would be able not only to study the station at the time given between the stations but also to read through it for possible complexities during the exam.

Certain folders containing the answer sheet, the guidelines of the exam and stickers marked with their codes were prepared for each student. The students were supposed to provide the tutors in 
Table I. The competencies evaluated in different tracks

\begin{tabular}{|lccccccc|}
\hline & 1 & 2 & 3 & 4 & 5 & 6 & 7 \\
\hline Morning 1 & CXR & NG tube insertion & Angiokit & Ear & Abdomen & Cranial nerves & Diabetes \\
\hline Morning 2 & Growth rate & Pap smear & Catheterization & Eye & Back pain & Cerebellum & Abdominal pain \\
\hline Afternoon & Blood test & Foreign body & Suturing & Thyroid & Mouth & Meningitis & Dermatology disease \\
\hline Category & Interpretation & Procedure & Procedure & $\begin{array}{c}\text { Physical } \\
\text { examination }\end{array}$ & $\begin{array}{c}\text { Physical } \\
\text { examination }\end{array}$ & $\begin{array}{c}\text { Physical } \\
\text { examination }\end{array}$ & History taking \\
\hline
\end{tabular}

each station with their sticker aiming to conceal the students' identity from the tutors.

At the same time, the students were fully informed about the exams; they received several guidelines on the basis of how an OSCE exam is performed. Some additional points were also provided for the applicants, aiming to encourage the active participation of the students. Considering religious issues, female students were asked to participate in the morning exam and the males were invited for the afternoon exam.

Considering the fact that there was no significant difference between the pre-internship scores of the male and female students ( $p=0.247)$, the girls were asked to participate in the morning exam while the boys attended the afternoon test.

The exam was held on 4 October 2008; 46 students participated in the morning session and 40 others in the afternoon shift. At the entrance, the students picked their folder, suggestive of the track they were going to participate in. An official was responsible to verify the identity of the students through checking their identity card. The students were then guided to the quarantine considering their group. Three individuals were responsible for guiding the students during the exam and through the stations.

\section{Statistical analysis}

Following the exam, the student's score in each station, his/her total score in the OSCE exam, and the pre-internship score (the score obtained in the MCQ exam that all Iranian medical students take before entering the internship) were all entered in SPSS version 15 and analyzed.

\section{Results}

Eighty-six students participated in the exam. The cooperation rate (COR) was about $88.6 \%$. The mean pre-internship score was $128.91 \pm 16.9$, ranging from 93 to 164 (total score 200).

Considering the points achieved in each track, the mean score in the morning exam was 4.39 and 4.44 whereas that for the afternoon exam was 3.90 and 3.75 points. The highest score in the morning exams were 5.6 and 5.52, and for the afternoon exams were 4.9 and 4.5 . The lowest scores, on the other hand, were 2.55 and 2.85 for the morning exams, and 2.65 and 1.7 for the afternoon.
Some students were able to score all 10 points in the following stations: performing Pap smear (47.8\%), inserting IV-line catheter (21.7\%), examining cerebellum (13\%), interpreting laboratory tests (5\%), examining cranial nerves (4.3\%), drawing and interpreting weight charts (4.3\%), and suturing (2.5\%). Conversely, extracting a foreign body (20\%), placing NG tube (8.9\%), and performing Pap smear $(4.3 \%)$ were among the stations in which some students could not obtain any points (0).

All the stations had a difficulty index of about 0.5; taking the history of a patient with abdominal pain (0.21) and inserting urinary catheter (0.26) were considered the most difficult stations, whereas performing Pap smear and examining cerebellum (0.71) were considered the easiest stations. All the stations, except for those designed to evaluate the competency in history taking in abdominal pain and dermatology disease, had an acceptable discriminative index (higher than 0.1).

The students gained the highest points in the history taking stations $(6.73 \pm 1.83)$, whereas the procedure stations accounted for the lowest points $(4.98 \pm 1.86)$; there was a significant difference between these stations except for the ones on physical examination and interpreting laboratory tests (Table II).

There was a strong positive association between the points achieved in the OSCE exam and the student's pre-internship exam score $(p<0.001)$. The Pearson correlation revealed a positive but weak correlation between the pre-internship score and

Table II. Comparing the students' competency in different stations

\begin{tabular}{|lcc|}
\hline Parameter & Mean \pm SD & Value of $p$ \\
\hline $\begin{array}{l}\text { History taking } \\
\text { - Physical examination }\end{array}$ & $6.73 \pm 1.83$ & 0.470 \\
\hline $\begin{array}{l}\text { History taking } \\
\text { - Interpretation }\end{array}$ & $6.73 \pm 1.27$ & \\
\hline History taking & $5.95 \pm 2.24$ & 0.018 \\
- Procedure & $6.73 \pm 1.83$ & $<0.001$ \\
\hline $\begin{array}{l}\text { Physical examination } \\
\text { - Interpretation }\end{array}$ & $6.98 \pm 1.86$ & \\
\hline Physical examination & $6.95 \pm 1.27$ & 0.238 \\
- Procedure & $6.26 \pm 1.27$ & $<0.001$ \\
\hline Interpretation & $4.98 \pm 1.86$ & \\
\hline - Procedure & $5.95 \pm 2.24$ & 0.002 \\
\hline
\end{tabular}


Table III. The scores obtained in different types of stations based on the student's gender

\begin{tabular}{|lccc|}
\hline Variables & Female (mean \pm SD) & Male (mean \pm SD) & Value of $p$ \\
\hline History taking & $7.47 \pm 1.5$ & $5.66 \pm 2.1$ & $<0.001$ \\
\hline Physical examination & $6.17 \pm 1.3$ & $6.38 \pm 1.3$ & 0.455 \\
\hline Interpretation & $5.94 \pm 2.4$ & $5.97 \pm 2.4$ & 0.951 \\
\hline Procedure & $5.65 \pm 1.8$ & $4.01 \pm 1.4$ & $<0.001$ \\
\hline
\end{tabular}

the score achieved in the OSCE exam $(0.371,0.212$, respectively).

The female students achieved significantly higher scores in the OSCE exam compared to males (4.32 \pm 0.7 vs. $3.88 \pm 0.6, p=0.004$ ); for the pre-internship, however, male students' scores were non-significantly higher $(127.86 \pm 16.4$ vs. $130.43 \pm 17.6$, $p=0.492$ ). The female students reportedly obtained higher scores in stations designed to evaluate their competencies in history taking and performing certain procedures (Table III).

\section{Discussion}

The present study showed that many of the undergraduate students do not have sufficient competency in performing the majority of clinical skills which they are in charge of during the internship. This is in line with the study performed in Shiraz University of Medical Sciences, which reported the incompetency of the students in performing clinical skills [11]. Based on its results, the average score of the clerks assessed through OSCE was half the total score [11]. Remmen et al. likewise assessed the competency of last-year medical students in performing 265 clinical skills through a questionnaire and found that they could not rely on their learned material in performing procedures later on during the internship [13].

Fox et al. compared the competency of PRHOs (pre-registration house officers) in performing 17 clinical skills through OSCE and questionnaire. They reported that the majority of these students are incapable of performing certain skills but neither they nor their supervisors are aware of their deficiencies [14].

Ringested et al. similarly evaluated the competency of the interns in doing clinical skills during the clerkship period through questionnaires. They reported that the undergraduate students' competency was less than average in the majority of the cases; they therefore concluded that revising the curriculum with the aim of improving the clerkship competency in performing clinical skills was needed [15]. The present study also revealed that students obtained the highest score in stations designed to assess their competency in taking history and then in performing physical examination, whereas the stations designed to evaluate the competency of procedures accounted for the lowest scores.
This was in accordance with the fact that the students are frequently asked to take complete histories and perform through physical examinations during clerkship in our country. During the internship, however, they are responsible for performing certain clinical skills and procedures - rarely taught or exercised throughout the clerkship - all by themselves and in the absence of any supervision. Amini et al. asked the interns studying in Tabriz University of Medical Sciences to evaluate their competency in performing certain procedures; the study revealed the majority of these undergraduate students to be incompetent in performing clinical skills. These students considered their capability in performing different clinical skills to be about $51.4 \%$, adding that they had insufficient competency in performing lumbar puncture, inserting tracheal and nasogastric tubes, placing a splint, and extracting a foreign body from the eye or ear, as they had learnt these skills through observation and practiced them in the absence of any supervision [16].

The girls obtained the highest score in the OSCE exam while the boys' score was higher in the preinternship exam, indicating that girls perform better in clinical skills whereas boys are more competent in knowledge exams. This could be attributed to the fact that boys spend less time learning skills when their outcomes are not assessed.

Considering the significant difference noted between the scores achieved in the OSCE exam and the pre-internship exam, it could be concluded that none of these exams can substitute one another in evaluating undergraduate medical students in our university.

In conclusion, this study reported the incompetency of medical students in performing certain clinical skills during internship, indicating that there is a great need to revise the current curriculum in order to focus on clinical skill development during the medical education.

Moreover, this exam provides reasonable evidence for the need of repeating a similar exam regularly at the end of the clerkship as well as at graduation time to confirm the competency of medical students entering the internship period and society.

This OSCE exam was the first such exam, performed at the end of the clerkship period, aiming to evaluate the curriculum at this stage rather than the students' competency; as a result, the authorities decided to provide some additional points to 
encourage students to participate in the exam. Such a strategy may have motivated weaker students more than stronger ones to attend the examination. However, considering the high cooperation rate of the present study, a sampling bias is not applicable.

Moreover, in deference to our country's segregation laws concerning educational environments, we had to ask the female students to attend the morning exam and the males to come in the afternoon. The stations designed for the morning and afternoon exams are believed to be similar regarding the competencies they assessed as well as their difficulty, but it would be a better idea to ask all the students to attend similar stations and thereafter evaluate the influence of gender on their scores.

\section{References}

1. Al-Naami MY. Reliability, validity, and feasibility of the objective structured clinical examination in assessing clinical skills of final year surgical clerkship. Saudi Med J 2008; 29: 1802-7.

2. Ladak A, Hanson J, de Gara CJ. What procedures are students doing during undergraduate surgical clerckship? Can J Surg 2006; 49: 329-34.

3. Association of American Medical Colleges. The AAMC Project on the Clinical Education of Medical Students. 20037-1127. 2028280505.

4. Elzubeir MA, Rizk DE. Assessing confidence and competence of senior medical students in an obstetrics and gynaecology clerkship using an OSCE. Educ Health (Abingdon) 2001; 14: 373-82.

5. Heckmann JG, Knossalla F, Gollwitzer S, Lang C, Schwab S. OSCE in the Neurology Clerkship. Fortschr Neurol Psychiatr 2009; 77: 32-7.

6. Mathews L, Menon J, Mani NS. Micro-OSCE for assessment of undergraduates. Indian Pediatr 2004; 41: 159-63.

7. Wu EH, Elnicki DM, Alper EJ, et al. Procedural and interpretive skills of medical students: experiences and attitudes of third-year students. Acad Med 2006; 81 (10 Suppl): S48-51.

8. Carr SJ. Assessing clinical competency in medical senior house officers: how and why should we do it? Postgrad Med J 2004; 80: 63-6.

9. Kazemi T, Hajiabadi Mohammad R. Study of status of clinical skill's education among interns of Birjand University of Medicine. J Med Educ 2006; 9: 99-103.

10. Haghdoost AA, Esmaeili A. The correlation between medical students' scores in their physiopathology and clinical courses in Kerman University of Medical Sciences. J Med Educ 2006; 10: 11-7.

11. OSCE in Clerckship. A report released by Shiraz University of Medical Sciences 2007 (Research).

12. Hamann C, Volkan K, Fishman MB, Silvestri RC, Simon SR, Fletcher SW. How well do second year students learn physical diagnosis? Observational study of an objective structured clinical examination (OSCE). BMC Medl Educ 2002; 2: 1.

13. Remmen R, Derese A, Scherpbier A, et al. Can medical schools rely on clerkships to train students in basic clinical skills? Med Educ 1999; 33: 600-5.

14. Fox RA, Ingham Clark CL, Scotland AD, Dacre JE. A study of pre-registration house officers' clinical skills. Med Educ 2000; 34: 1007-12.
15. Ringsted C, Schroeder TV, Henriksen J, et al. Medical students' experience in practical skills is far from stakeholders' expectations. Med Teach 2001; 23: 412-6.

16. Amini A, Barzegar M, Hatami Sad Abadi F. Analysis of the situation of practical clinical skills during internship of Tabriz University of Medical Sciences. Med Educ 2003; 4. 